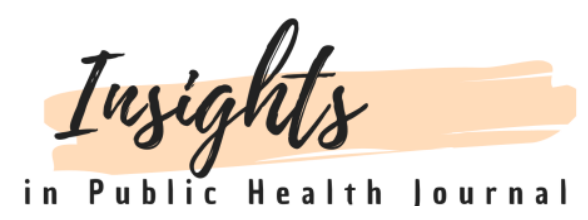

\title{
Perspective
}

\section{Informal Caregiving in Singapore: Macroeconomic Realities and Measures}

\author{
Wayne Freeman Weien Chong ${ }^{1,2 *}$ \\ ${ }^{1}$ Nanyang Technological University, Singapore, Singapore, Singapore. \\ ${ }^{2}$ GeroPsych Consultants Pte Ltd, Singapore, Singapore, Singapore. \\ ${ }^{*}$ Corresponding author: Wayne Freeman Weien Chong. \\ Email: wayn0002@ntu.edu.sq; wayne@geropsych.sg
}

\begin{abstract}
The very rapid ageing of Singapore's population is placing a huge burden on informal caregivers. I discuss two macroeconomic strategies - strengthening redistributive measures and professionalizing informal caregiving - that may alleviate this burden. A national study on informal caregiving is urgently required to identify specific areas and caregiver segments that will benefit from these strategies.
\end{abstract}

Keywords: informal caregiving, long-term care, Singapore, macroeconomic, workforce issues

By 2030 , one in four Singapore residents is projected to be 65 years or older. ${ }^{1}$ This rising number of older adults is likely to be accompanied by a corresponding increase in the number of individuals who will require assistance in daily living. Long-term care (LTC) services have become more well-known in the past decade, but utilization rates remain suboptimal except for nursing homes. ${ }^{2}$
Despite strong efforts in expanding LTC capacity in Singapore, informal caregivers, typically a family member or friend, continue to be de facto care providers. In 2010, approximately $8 \%$ of residents between the ages of 18 and 69 years provided care to a friend or family member. ${ }^{3}$

\section{Informal caregiving is costly}

From a macroeconomic perspective, the costs and opportunity costs of unpaid informal caregiving are substantial. Unpaid informal caregivers of older adults not only pay the lion's share of the mental, emotional, social, and financial costs of care, ${ }^{4,5}$ they also fork out non-trivial opportunity costs associated with care provision: lost wages, desired lifestyles, personal freedom, and aspirations. ${ }^{6,7}$

In the United States, the economic value of informal caregiving contributions was estimated at US $\$ 67$ billion in 2019, which by 2050 will likely double to between US $\$ 132$ billion to US $\$ 147$ billion. Each caregiver's average opportunity cost in the United States will likely rise by eight to 20 percent. $^{8}$ Informal caregivers save the economy up to US\$642 
billion per annum in the United States, ${ }^{9}$ and $£ 132$ billion per annum in the United Kingdom. ${ }^{10}$

While the total value of informal caregiving in Singapore is unavailable, about 12,500 residents cited family caregiving to families or relatives as the main reason for leaving their job and not looking for a job from 2015 to 2017. Most of these residents were women, 40 year and over, and married. ${ }^{11}$

\section{Strengthen redistributive measures}

The Singapore government has, in recent years, implemented a slew of financial measures aimed at better supporting family caregivers. These measures include the provision of a $\$ 200$ annual caregiver training subsidy, and a $\$ 200$ monthly home caregiving grant, and the expansion of an employeeemployer-state endowed social security fund to cover siblings as dependents. ${ }^{12}$

Sadly, well-intentioned public education messages that remind family caregivers to seek help often also carries this subtle, underlying and inadvertently unempathetic message to our unsung heroes: you should be responsible for the care of your loved one and yourself.

To nurture an inclusive society with rapidly growing numbers of older persons and informal caregivers, could Singapore move from financial support to financial compensation and recognition of family caregivers?

For instance, a caregiver allowance compensates for the reduced employment income and pays for out-of-pocket caregiving expenses. Similarly, legislated family care leave or caregiving leave would allow employees to remain remunerated while one takes several days off to care for an older relative. Or how about a cash incentive held by disabled older persons that could be used by this person to support or even hire family members to provide informal care?

The success of these measures would depend on the government's ability to finetune or expand the criteria already in place for the identification of caregivers and the justification of care needs. The experiences of nations that have longer histories of redistributive policies in ageing societies, such as those in the Organization for Economic Co-operation and Development, could also be consulted. ${ }^{13}$

Such redistributive measures promote the independence of the older adults and facilitate ageing-in-place. They recognize the costs and opportunity costs paid by caregivers and send a strong signal that caregivers play an important social-economic role. Macroeconomically, such measures are justifiable transfers from the national economic savings to informal caregivers who contributed to these savings.

\section{Professionalize home-based caregiving}

In Singapore, foreign domestic helpers performed a significant share of informal caregiving tasks. ${ }^{14,15}$ These workers from less affluent neighbouring nations such as Indonesia and the Philippines are neither trained nor enabled to provide care. However, they are tasked with assisting older adults and disabled individuals with activities of daily living, which are often undertaken in addition to domestic chores.

That domestic helpers has been perceived as the most viable source of informal caregiving, ${ }^{16}$ and that families with higher household income and educational level and more expensive housing type rather than level of care need were more likely to employ them, ${ }^{17}$ show that the skills of home-based informal caregiving are undervalued in Singapore.

To recognize the value that quality informal caregiving contributes to age-in-place, the 
skillsets a caregiver should possess must first be matched to the assistance that the care recipient requires physically and psychosocially. A skills framework, together with an industry transformation map, could be initiated to certify would-be foreign and family caregivers with various home caregiving skills at incremental levels of proficiencies. This measure not only alleviates the burden of unpaid caregiving, but it also creates sustainable employment opportunities in the care sectors, which in turn prepares the national healthcare system for the needs brought about by ageing.

\section{Make evidence-based policy}

The increasing need for informal caregiving of older adults in Singapore has become a wicked problem, and should be tackled expeditiously.

To enact a robust and well-calibrated policy that compensates informal caregivers and professionalizes home-based caregiving, a second national population-based investigation on informal caregiving should be performed. This study shall inform on the costs, opportunity costs, health, and wellbeing associated with informal caregiving of older adults in Singapore. Difficult questions such as the following should be addressed.

How many informal caregivers are there in Singapore? What out-of-pocket items and at what cost do they pay, to care for an older adult at home? How could caregiver burden be quantified and addressed sustainably? What technical competencies have caregivers acquired due to caregiving, and to what levels of proficiency?

Caregivers health and well-being may vary in tandem with the care recipient's recovery journey. ${ }^{18,19}$ Recent research found that Singapore caregivers of stroke survivors who were distressed at hospital discharge had a $24 \%$ likelihood of remaining distressed 12 months after discharge..$^{20,21}$ The proposed national study should include a time dimension, and ask if caregiver well-being fluctuates similarly when the care recipient suffers from other chronic conditions or disabilities, and if this trend persists over a longer time horizon.

Apart from answering these questions, a national investigation on informal caregiving could also point to potential solutions to yet-tobe-resolved issues surfaced by the previous study on informal caregiving, such as employed caregivers facing heavy demands on their time. ${ }^{16}$

Some of the above questions were raised in Parliament but were not adequately addressed due to lack of data. ${ }^{11}$ With a longitudinal national study that considers variations in informal caregiving arrangements across factors such as type of household and chronic illnesses, subsequent parliamentary debates on this topic would become more insightful and consequent policy solutions would be evidence based.

\section{REFERENCES}

1. National Population and Talent Division, Singapore. Population in Brief 2019 [Internet]. 2020. [cited 2020 Nov 30]. Available from: https://www.population.sg/articles/oldersingaporeans-to-double-by-2030

2. Ministry of Health, Singapore. Utilisation of Leong Term Care Services 2019 [Internet]. 2019. [cited 2020 Nov 30]. Available from https://www.moh.gov.sg/newshighlights/details/utilisation-of-long-term-careservices

3. Zheng Z. Caregiving in Singapore [Internet]. Singapore: Ministry of Health; 2011. [cited 2020 Nov 30]. Available from: https://www.singstat.gov.sg//media/files/publications/society/ssnsep11pg12-14.pdf

4. Reinhard SC, Feinberg LF, Houser A, Choula R, Evans M. Valuing the invaluable 2019 update: 
charting a path forward [Internet]. United States of America: AARP Public Policy Institute. [cited 2020 Nov 30]. Available from: https://www.aarp.org/ppi/info-2015/valuing-theinvaluable-2015-update.html

5. Roth DL, Fredman L, Haley WE. Informal caregiving and its impact on health: a reappraisal from population-based studies. Gerontologist. 2015;55(2):309-319. doi:10.1093/geront/gnu177

6. Jacobs JC, Van Houtven C,H., Tanielian T, Ramchand R. Economic Spillover Effects of Intensive Unpaid Caregiving. Pharmacoeconomics 2019;37(4):553-562.

7. Wee S-L, Hu AJ, Yong J, Chong WF, Raman P, Chan A. Singaporeans' Perceptions of and Attitudes Toward Long-Term Care Services. Qualitative Health Research. 2015;25(2):218227. doi:10.1177/1049732314549812

8. Mudrazija S. Work-related opportunity costs of providing unpaid family care in 2013 and 2050 . Health Aff. 2019;38(6):1003-1010. doi:10.1377/hlthaff.2019.00008

9. Chari AV, Engberg J, Ray KN, Mehrotra A. The opportunity costs of informal elder-care in the United States: new estimates from the American time use survey. Health Serv Res. 2015;50(3):871-881. doi: 10.1111/14756773.12238

10. CarersUK. Facts and figures [Internet]. United Kingdom: CarersUK; [cited 2020 Nov 30]. 2019. Available from:

https://www.carersuk.org/news-andcampaigns/press-releases/facts-and-figures

11. Ministry of Health, Singapore. Update on the current number of informal and professional caregivers in Singapore [Internet]. 2019. [cited 2020 Nov 30]. Available from: https://www.moh.gov.sg/news-

highlights/details/updates-on-the-currentnumber-of-informal-and-professionalcaregivers-in-singapore

12. Ministry of Health, Singapore. Caregiver support [Internet]. 2019. [cited 2020 Nov 30]. Available from: https://www.moh.gov.sg/caregiver-support
13. Organisation for Economic Co-operation and Development. Policies to support family carers [Internet]. 2010. [cited 2020 Nov 30]. Available from: $\quad$ https://www.oecd.org/els/healthsystems/47884889.pdf

14. Ministry of Manpower, Singapore. Foreign workforce numbers [Internet]. 2020. [cited 2020 Nov 30]. Available from https://www.mom.gov.sg/documents-andpublications/foreign-workforce-numbers

15. Harding SA, Chan A. A profile of older men and women in Singapore 2014 [Internet]. Singapore: International Longevity Centre, Tsao Foundation Singapore; 2014. [cited 2020 Nov 30]. Available from http://www.ilcalliance.org/images/uploads/publicationpdfs/A_profile_of_older_men_and_women_in_ singapore_2014.pdf

16. Chan A, Østbye T, Malhotra R, Hu AJ. Report of the survey on informal caregiving [Internet]. Singapore: Ministry of Social and Family Development; 2012. [cited 2020 Nov 30]. Available from: https://www.msf.gov.sg/publications/Pages/The -Survey-on-Informal-Caregiving.aspx

17. Rozario PA, Hong SI. Foreign Domestic Workers and Eldercare in Singapore: Who Hires Them?. J Aging Soc Policy. 2019;31(3):197210. doi:10.1080/08959420.2019.1578605

18. Visvanathan A, Mead G, Dennis M, Whiteley W, Doubal F, Lawton J. Maintaining hope after a disabling stroke: A longitudinal qualitative study of patients' experiences, views, information needs and approaches towards making treatment decisions. PLoS One. 2019;14(9):e0222500.

doi:10.1371/journal.pone.0222500

19. Shaffer KM, Kim Y, Carver CS. Physical and mental health trajectories of cancer patients and caregivers across the year post-diagnosis: a dyadic investigation. Psychol Health. 2016;31(6):655-674. doi:10.1080/08870446.2015.1131826

20. Chong WF, Ng LH, Ho HMR, Koh CHG, Hoenig $\mathrm{H}$, Matchar DB, et al. Stroke rehabilitation use and caregiver psychosocial health profiles in 
Singapore: A latent profile transition analysis 2020. doi:10.31219/osf.io/txe89.

21. Chong WFW. Formal Long-Term Care: Informal Caregivers' Subjective Well-Being and Service Utilization. International Journal of Integrated Care. 2020;20(3):11. DOI: http://doi.org/10.5334/ijic.5565 